\title{
Commentary on “Does Seeing One Another's Gaze Affect Group Dialogue? A Computational Approach"
}

\author{
H. Ulrich Hoppe \\ University of Duisburg-Essen, Germany \\ hoppe@collide.info
}

\begin{abstract}
This commentary elaborates on the role of "grounding" as a focal theoretical concept and aims to contextualize the claims formulated by Schneider and Pea (2015, this issue) in previous CSCL discussions. It provides fingerposts for enriching and refining the concept of grounding from a pedagogical point of view. It also suggests using the mutual awareness of eyegaze in the context of dialogical learning.
\end{abstract}

KEYWORDS: Eye-gaze, grounding, multi-vocal interaction analysis, CSCL

\section{INTRODUCTION}

The paper by Schneider and Pea (2015, this issue) studies the use of eye-tracking to support collaborative learning and introduces an analytic approach that combines the analysis of eye-tracking data with NLP-based analyses of collaborative discourse. Several data mining techniques are also employed, which altogether makes this paper very relevant to learning analytics research. The authors frame their approach as an example of new combinations of computational methods that can facilitate and advance the empirical study of collaborative learning from a learning analytics perspective. Indeed, I see this paper as a good and innovative example of this new line of research.

In this commentary, I try both to scrutinize and to extrapolate the claims made in this paper regarding the potential for intersecting CSCL and learning analytics research. I focus especially on the notion of "grounding" as a theoretical reference point and as a source of inspiration to develop indicators or "markers" that can be considered relevant from an educational perspective.

\section{2 “GROUNDING” AS A THEORETICAL REFERENCE FRAME}

In its theoretical underpinning, the paper centrally refers to the notion of "grounding" in the sense of Clark and Brennan (1991). The concept of grounding has been introduced to explain discourse on the level of sequences of utterances, yet it does not come with direct pedagogical implications. The "technical" or operational nature of grounding is very clearly expressed in Brennan, Chen, Dickinson, Neider, and Zelinsky (2008):

"the grounding framework ... proposes that partners in a collaborative task monitor and coordinate their behaviour to minimize their collective effort, as well as the costs that arise in joint activity" (p.1466). 
(2015). Commentary on "Does Seeing One Another's Gaze Affect Group Dialogue? A Computational Approach". Journal of Learning Analytics, 2(2), 134-137. http://dx.doi.org/10.18608/jla.2015.22.10

In this sense, the concept of grounding describes mechanisms similar to those used to ensure safe communication in technical systems. Some interpretations and adaptations in the CSCL community have identified grounding with "shared understanding" on a higher semantic or knowledge level. Schneider and Pea use this assumption in their introduction to the notion of "coherence" (see first paragraph of section 4.3). However, the identification of grounding with shared understanding has been explicitly challenged by Cherubini, Van Der Pol, and Dillenbourg (2005) from an educational perspective in an article entitled "Grounding is not Shared Understanding." Cherubini et al. make the point that the identification of "co-referenced actions" alone does not directly lend itself to knowledge-level interpretations relevant for learning. They claim that additional constructs are needed to warrant such interpretations, which would include the identification of different perspectives and shifts of perspective. Although being less explicit than Cherubini et al. regarding the distinction of grounding and shared understanding, Dillenbourg and Traum (2006) introduce different levels of the "mutuality of knowledge": 1) access, 2) perception, 3) understanding, and 4) agreement. These levels indicate a progression from syntactic to semantic and pragmatic aspects of mutuality. The original notion of grounding clearly includes the syntactic level in which coordination prevails over the mutual congruence of semantic interpretations. The concept of "convergence" as adopted by Schneider and Pea would likely be allocated on a lower syntactic level whereas "coherence" would be understood as semantic agreement. The point here is that the paper lacks such distinctions. A further differentiation of such constructs and of the ensuing operational indicators or "markers" may lead to clearer insights about educationally relevant processes of interaction and mutual knowledge building (which should necessarily be all subsumed as "shared understanding").

The mix of computational methods of analysis proposed by Schneider and Pea is naturally compatible with a learning analytics approach in which eye-gaze is a specifically innovative ingredient. However, from a CSCL point of view, one might expect the methodological proposition to be more explicitly rooted in a theoretical framework. I have argued that a stronger theoretical underpinning might already come from a more differentiated and contextualized perspective on grounding and shared understanding in educational scenarios. On the other hand, one avenue of research in the CSCL community is the notion of "multi-vocal interaction analysis" (Suthers, Lund, Rosé, Teplovs, \& Law, 2013) to which the approach of Schneider and Pea could be beneficially related and compared. The approaches of Suthers, Dwyer, Medina, and Vatrapu (2010) and Trausan-Matu (2013) especially can serve as examples of formalcomputational frameworks that come with a theoretical underpinning and provide a coherent interpretation of collaborative interactions in terms of "contingency relations between utterances" (Suthers) or "polyphonic" variations on lexico-semantic themes in collaborative discourse (TrausanMatu).

\section{FROM INTERACTION DESIGN TO PEDAGOGY}

The study of Schneider and Pea contributes to interaction design as well as to computational methods of learning analytics. In both aspects, eye-gaze is an important ingredient. As for the interaction design, the 
(2015). Commentary on "Does Seeing One Another's Gaze Affect Group Dialogue? A Computational Approach". Journal of Learning Analytics, 2(2), 134-137. http://dx.doi.org/10.18608/jla.2015.22.10

focal point is the mutual awareness of eye-gaze. In the experimental design, the "visible gaze" condition is contrasted with a quite poor audio-based communication (volatile, without "external memory"). It is evident that the absence of deictic reference in the control condition makes communication about the content of the visually presented materials much more difficult. The following example (utterance from group 6, (p. 124) shows that visible gaze can be and was indeed used as a substitute of deictic reference: "Um, well it's not the one you're looking at right now."

Regarding this point, the authors state

"We agree that a third condition, where students could create shared annotations or see the cursor of their partner, would enable teasing apart the effects of seeing the gaze of one's collaborator at all times, and the effects of having a common deictic pointer. ... We hypothesize that the gaze-awareness condition nonetheless offers advantages compared to a "visible mouse cursor" condition" (p. 129).

There is no doubt that mutual awareness of eye gaze supports coordinated action (see Brennan et al., 2008), and also that the type of awareness induced by mutual eye-gaze is different from the one of telepointing. Indeed, tele-pointing is a direct, intentional method of conveying information on the current "focus of attention" from one actor to another (or others), whereas mutual eye-gaze awareness involves a second-person perspective in which the receiver has to interpret the awareness signal in the context of the originator's logic of actions. From a pedagogical point of view, this second-person perspective could be traced back to old principles of designing "clarifying educational environments" as formulated by Moore and Anderson (1968). Taking the mutual second-person perspective as a specific focus could lead into the field of "dialogical learning" with roots in Martin Buber's philosophy of dialogue (see Kramer, 2013, for an educational contextualization). From a more up-to-date CSCL point of view, the works of Wegerif $(2006,2007)$ and Slakmon and Schwartz (2014) are certainly relevant to this perspective. Mutual awareness of eye-gaze should perfectly fit in with dialogic learning scenarios as a design element, but also computational indicators of the type suggested by Schneider and Pea could particularly be adopted to pinpointing dialogic interactions from an analytic perspective.

\section{SUMMARY}

In their article, Schneider and Pea exemplify relevant and interesting aspects of what computational techniques of learning analytics can bring to the study of collaborative learning. Blending different lexico-semantic and syntactic methods to define "markers" for significant episodes or acts of learning is certainly of high interest, and combining analyses based on eye-gaze data with linguistic methods is particularly promising.

For one part, my suggestions aim at refining the notion of grounding used as a theoretical reference as well as differentiating the corresponding technical constructs in terms of markers or indicators, also addressing more explicitly the specific implications that come with a pedagogical usage context. Certainly a bit more speculative is the idea of combining the specific affordances of mutual eye-gaze awareness with dialogic learning, both from a facilitation and an analytics point of view. 
(2015). Commentary on "Does Seeing One Another's Gaze Affect Group Dialogue? A Computational Approach". Journal of Learning Analytics, 2(2), 134-137. http://dx.doi.org/10.18608/jla.2015.22.10

\section{REFERENCES}

Brennan, S. E., Chen, X., Dickinson, C. A., Neider, M. B., \& Zelinsky, G. J. (2008). Coordinating cognition: The costs and benefits of shared gaze during collaborative search. Cognition, 106(3), 1465-1477.

Cherubini, M., Van Der Pol, J., \& Dillenbourg, P. (2005, July). Grounding is not shared understanding: Distinguishing grounding at an utterance and knowledge level. Paper presented the the Fifth International and Interdisciplinary Conference on Modeling and Using Context, CONTEXT '05., Paris, France. Retrieved from https://telearn.archives-ouvertes.fr/hal-00190089

Clark, H. H., \& Brennan, S. E. (1991). Grounding in communication. In L. B. Resnick, J. Levine, \& S. D. Behrend (Eds.), Perspectives on socially shared cognition (pp. 127-149). Washington, DC: American Psychological Association.

Dillenbourg, P., \& Traum, D. (2006). Sharing solutions: Persistence and grounding in multimodal collaborative problem solving. The Journal of the Learning Sciences, 15(1), 121-151. http://dx.doi.org/10.1207/s15327809jls1501_9

Kramer, K. P. (2013). Learning through dialogue: The relevance of Martin Buber's classroom. Lanham, MD: R\&L Education.

Moore, O. K., \& Anderson, A. R. (1968). Some principles for the design of clarifying educational environments. In D. Goslin (Ed.), Handbook of socialization theory and research (pp. 571-613). New York: Rand-McNally.

Schneider, B., \& Pea, R. (2015, this issue). Does seeing one another's gaze affect group dialogue? A computational approach. Journal of Learning Analytics, 2(2), 107-133. http://dx.doi.org/10.18608/jla.2015.22.9

Slakmon, B., \& Schwarz, B. B. (2014). Disengaged students and dialogic learning: The role of CSCL affordances. International Journal of Computer-Supported Collaborative Learning, 9(2), 157-183. http://dx.doi.org/10.1007/s11412-014-9191-x

Suthers, D. D., Dwyer, N., Medina, R., \& Vatrapu, R. (2010). A framework for conceptualizing, representing, and analyzing distributed interaction. International Journal of ComputerSupported Collaborative Learning, 5(1), 5-42. http://dx.doi.org/10.1007/s11412-009-9081-9

Suthers, D. D., Lund, K., Rosé, C. P., Teplovs, C., \& Law, N. (Eds.). (2013). Productive multivocality in the analysis of group interactions. New York: Springer.

Trausan-Matu, S. (2013). Collaborative and differential utterances, pivotal moments, and polyphony. In D. Suthers et al. (Eds.), Productive multivocality in the analysis of group interactions (pp. 123139). New York: Springer.

Wegerif, R. (2006). A dialogic understanding of the relationship between CSCL and teaching thinking skills. International Journal of Computer-Supported Collaborative Learning, 1(1), 143-157. http://dx.doi.org/10.1007/s11412-006-6840-8

Wegerif, R. (2007). Dialogic education and technology: Expanding the space of learning (Vol. 7). New York: Springer Science \& Business Media. 